\title{
Environmental Impact of Urban Consumption Patterns: Drivers and Focus Points
}

\author{
Kalbar, Pradip P.; Birkved, Morten; Hauschild, Michael Zwicky; Kabins, Simon; Nygaard, Simon Elsborg
}

Published in:

Resources, Conservation and Recycling

Link to article, DOI:

10.1016/j.resconrec.2018.06.019

Publication date:

2018

Document Version

Peer reviewed version

Link back to DTU Orbit

Citation (APA):

Kalbar, P. P., Birkved, M., Hauschild, M. Z., Kabins, S., \& Nygaard, S. E. (2018). Environmental Impact of Urban Consumption Patterns: Drivers and Focus Points. Resources, Conservation and Recycling, 137, 260-269. https://doi.org/10.1016/j.resconrec.2018.06.019

\section{General rights}

Copyright and moral rights for the publications made accessible in the public portal are retained by the authors and/or other copyright owners and it is a condition of accessing publications that users recognise and abide by the legal requirements associated with these rights.

- Users may download and print one copy of any publication from the public portal for the purpose of private study or research.

- You may not further distribute the material or use it for any profit-making activity or commercial gain

- You may freely distribute the URL identifying the publication in the public portal 


\title{
Environmental Impact of Urban Consumption Patterns: Drivers and Focus Points
}

\author{
Pradip P. Kalbar ${ }^{1,2 \star}$, Morten Birkved ${ }^{3}$, Michael Hauschild ${ }^{3}$, Simon Kabins ${ }^{4}$ and Simon Elsborg \\ Nygaard ${ }^{4}$ \\ ${ }^{1}$ Centre for Urban Science and Engineering (CUSE), Indian Institute of Technology Bomba, Powai, \\ Mumbai 400 076, India. \\ ${ }^{2}$ Interdisciplinary programme (IDP) in Climate Studies, Indian Institute of Technology Bomba, Powai, \\ Mumbai 400 076, India. \\ ${ }^{3}$ Quantitative Sustainability Assessment Division, DTU Management Engineering, Technical \\ University of Denmark, Denmark \\ ${ }^{4}$ Department of Psychology and Behavioral Sciences, BSS, Aarhus University, Denmark
}

\section{*Corresponding author:}

Pradip P. Kalbar

Centre for Urban Science and Engineering (CUSE),

Associated Faculty - Interdisciplinary programme (IDP) in Climate Studies

Indian Institute of Technology Bombay

Powai, Mumbai 400 076, India.

Office Tel.: +912225769330

Email: kalbar@iitb.ac.in;

\section{Abstract:}

The purpose of our study is to analyse how urban lifestyles impact on the environment to offer knowledge based inspiration for effective environmental policies relating to contemporary Danish consumption patterns. The application of a Personal Metabolism (PM) coupled Life Cycle Assessment (LCA) approach supported by cluster analysis facilitated the identification of consumption-related clusters based on central demographic and life style parameters such as income, diet, transport, and age. The environmental performance of the assessed consumption patterns were calculated in a full life cycle perspective and covering all relevant environmental impacts both on midpoint and endpoint levels by applying the ReCiPe 2008 Life Cycle Impact Assessment (LCIA) methodology. The results of the contribution analysis revealed that climate change, particulate matter, human toxicity, fossil depletion and ionizing radiation contribute most to the three endpoints covered by ReCiPe 2008 . Results of cluster analysis indicated that demographic parameters such as income level and age of the respondents has a strong influence on the environmental impacts. The influence of lifestyle aspects such as choice of diet, use of private car and household size was also investigated. These three parameters were found to significantly influence the consumption related environmental impacts of urban Danish residents. Overall our study identify drivers and focus points of consumption and provides a contemporary picture of Danish urban consumption-related environmental impacts.

Key words: Personal metabolism; Sustainable Consumption; Resource consumption; Life cycle assessment; Sustainability assessment; Urban Consumption 
Kalbar, P. P., Birkved, M., Hauschild, M. Z., Kabins, S., \& Nygaard, S. E. (2018). Environmental I mpact of Urban Consumption Patterns: Drivers and Focus Points. Resources, Conservation and Recycling 137, $260-269$. DOI: $10.1016 /$ j.resconrec.2018.06.019

\section{Introduction}

Urbanization is an ever growing global trend as more than $54 \%$ of the world's population is residing in urbanized areas (UN, 2014). The most urbanized areas include North America (82\%), Latin America and the Caribbean (80\%), and Europe (73\%) (UN, 2014). Data covering the past few decades show that human growth, economic development, and consumption of natural resources and degradation of natural ecosystems are coupled. This urban development poses a decoupling challenge at many levels, including policies motivating for changes in production processes and human lifestyles (UNEP, 2015). Past studies show that in order to be able to successfully mitigate the substantial environmental challenges that humanity is facing, it is necessary to take into account behavioural complexity, behavioural groupings, and lifestyle types (Baiocchi et al., 2010; Gilg and Barr, 2006).

It is also important to understand which components of consumption affect the environment most and what types and magnitudes of impacts the individual components are causing. Lahteenoja et al. (2007) estimated the Material Input Per Service unit (MIPS) for a typical Finnish households by studying the resource consumption patterns of 30 Finish households. The study took into account the material requirements for housing, food and beverages, transport, leisure time activities, tourism, and household goods and devices. Newton and Meyer (2012) studied the problem of urban resource consumption (water, energy, domestic appliances, travel, and housing space were all included in the study) by analyzing how much of the resource consumption is attributed to cities and housing and how much is directly associated with the individual behaviour of the consumer. The study concludes that urban resource consumption is more affected by contextual (household, dwelling and locational) factors than individual (structural and attitudinal) factors. There have been past attempts to apply Input Output (IO) models to estimate the carbon footprint of urban resource consumption (Schmidt et al., 2010; Schmidt and Muños, 2014). In a UK study by Druckman and Jackson (2009), a socioeconomically disaggregated quasi-multi-regional $1 \mathrm{O}$ model was applied to estimate $\mathrm{CO}_{2}$ embedded in goods and services purchased by households, $\mathrm{CO}_{2}$ due to direct fuel use by households; $\mathrm{CO}_{2}$ due to personal vehicle use, and; $\mathrm{CO}_{2}$ due to personal aviation.

Most of the above studies use carbon footprint as an impact indicator for the resource consumption of urban residents. Many studies focus only on one particular aspect such as water, food or energy consumption (Kenway et al., 2011; Wentz and Gober, 2007; Westhoek et al., 2014; Zhao et al., 2012). Leach et al. (2016) applied carbon, nitrogen and water footprint for food products and developed a labels for food products. One common denominator among these studies is that that there appears to be a lack of attempts to utilize the Life Cycle Assessment (LCA) in such consumption related studies. Our paper exactly fill this gap by coupling a consumption study with LCA. Recently, Mirabella et al. (2018) presents detailed account of relevant studies on this topics and highlights the need for such an LCA orientated effort.

Kalbar et al. (2016) presented a comprehensive model capable of assessing the annual metabolic consumption flows of Danish residents. LCA to conduct environmental assessment of the material and energy flows resulting from consumption on an individual level, here referred to as Personal 
Kalbar, P. P., Birkved, M., Hauschild, M. Z., Kabins, S., \& Nygaard, S. E. (2018). Environmental I mpact of Urban Consumption Patterns: Drivers and Focus Points. Resources, Conservation and Recycling 137, $260-269$. DOI: $10.1016 /$ j.resconrec.2018.06.019

Metabolism (PM). The study illustrates how different consumption components may affect the environmental burden exerted by urban consumption patterns. The study also explores how some of the lifestyle aspects, such as choice of diet, use of private car and household size, may affect the environmental impacts resulting from urban consumption patterns. However, the study is limited to impact profiles on midpoint level impacts. To understand and better communicate the actual environmental and human health damages as well as resource depletions induced by the consumption patterns of urban dwellers, it is essential to include the results on an endpoint level as well as overall environmental impact indicator expressed in terms of an aggregated single score.

In this paper we report the results obtained by application of the PM-LCA model presented in details by Kalbar et al., (2016) at endpoint level. In addition our paper illustrates and discusses how different consumption components affect the environmental impacts at endpoint level. Further, consumption component contributions at midpoint level and endpoint level were compared, contrasted and subsequently interpreted. The paper also identifes drivers for consumption and focus points for reducing environmental impacts from the urban consumption. Finally, the effects of demographic factors and lifestyle aspects on the environmental impact exerted by urban consumption patterns were studied.

\section{Methodology}

The present study is based on the results from the coupled PM-LCA model presented in Kalbar et al., (2016). Figure 1, illustrates how the PM-LCA model was applied to quantify the impacts of the resource consumption of urban Danish residents taking into account the entire life cycle of the material and energy flows associated with their life style and consumption pattern. Information about the latter was gathered in a questionnaire survey. The data regarding housing, energy (thermal energy and electricity), road transportation, air travel, food consumption, expenditures related to products and services, recycling habits, and related sustainability behaviour factors were collected among 1283 respondents who all completed a detailed questionnaire. Further details about the respondents are provided in Kalbar et al. (2016). 
Kalbar, P. P., Birkved, M., Hauschild, M. Z., Kabins, S., \& Nygaard, S. E. (2018). Environmental Impact of Urban Consumption Patterns: Drivers and Focus Points. Resources, Conservation and Recycling 137, 260-269. DOI:

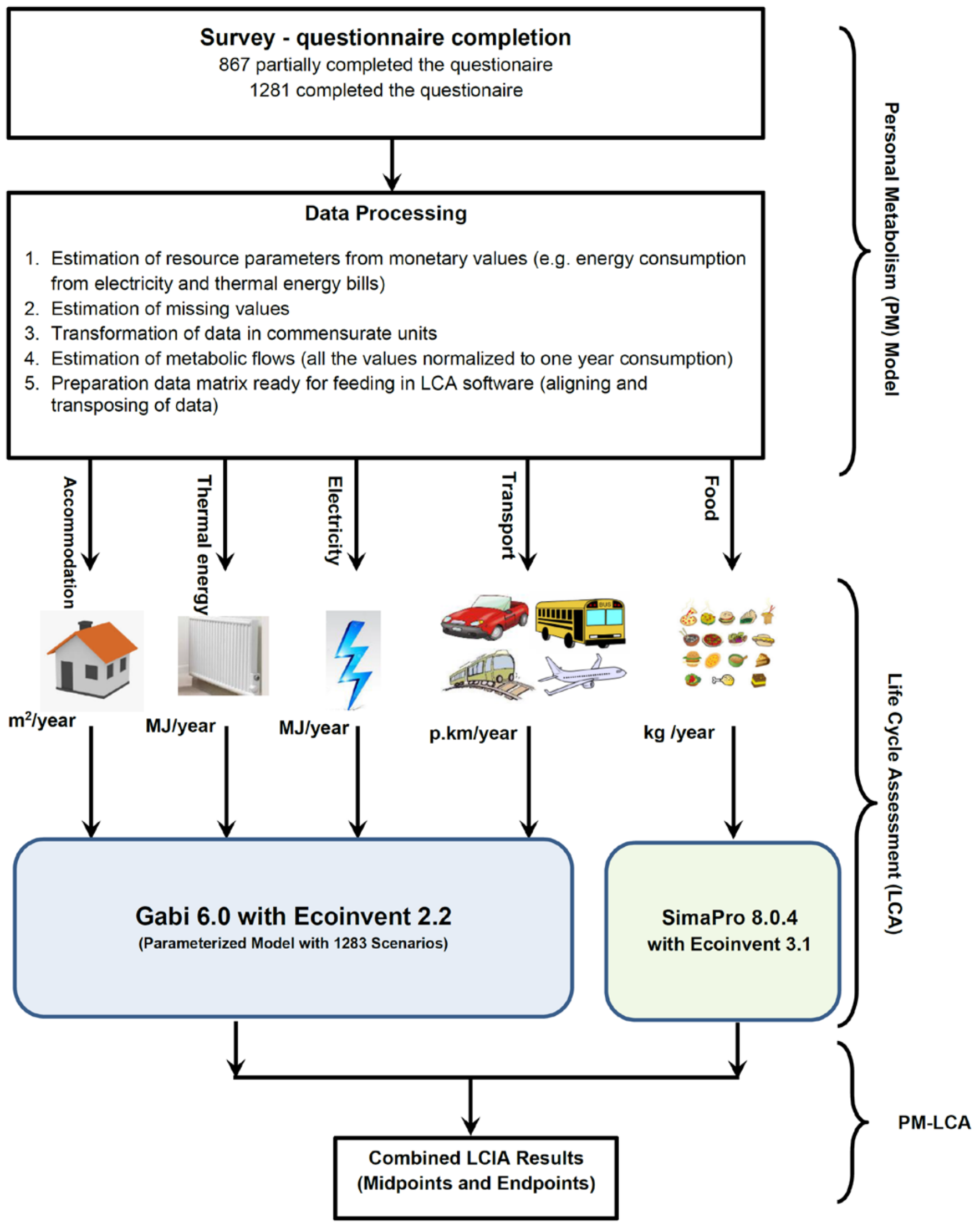

Figure 1: The modelling approach followed for estimating environmental footprint of urban residents using Personal Metabolism (PM) coupled with Life Cycle Assessment (LCA) (adapted from Kalbar et al. 2016) 
Kalbar, P. P., Birkved, M., Hauschild, M. Z., Kabins, S., \& Nygaard, S. E. (2018). Environmental I mpact of Urban Consumption Patterns: Drivers and Focus Points. Resources, Conservation and Recycling 137, $260-269$. DOI: $10.1016 /$ j. resconrec. 2018.06.019

Yearly consumption patterns were estimated for the 1283 respondents using the basic data from the questionnaire. The consumption patterns were used to parameterize the PM model. The environmental impacts related to the consumption flows were calculated using LCA. For accommodation a standard single family house was modelled in the Gabi 6.0 LCA software (Gabi, 2013) using the Ecoinvent 2.2 database (Ecoinvent, 2010) including production of all the materials required for the construction of the house as well as disposal of the building materials at the end of their service life. Standard processes available in the Ecoinvent 2.2 database for thermal energy, electricity, road transport (diesel and petrol cars meeting various Euro norms, public transport by bus and train) and person transport by air travel were used to model and quantify the environmental impacts related with consumption of these commodities and services. Environmental impacts related to production and consumption of food were modelled using the Simapro 8.0.4 LCA software (Simapro, 2014) with the Ecoinvent 3.1 database (Ecoinvent, 2014).

The ReCiPe 2008 impact assessment method applying the hierarchical perspective (Goedkoop et al., 2008) was used. The method calculates impacts at both midpoint and endpoint in the environmental mechanism for all emissions occurring in the life cycle. Midpoint results represent potential environmental impacts (e.g. global warming potential, eutrophication potential) where as endpoint results represent damages to the protection areas (human health, ecosystem and resources). The impact results for all mid- and endpoint indicators were estimated separately for each consumption component (accommodation, thermal energy, electricity, road transport, air travel and food). The midpoints and end-points were normalized using the normalization references of average European person with Hierarchist perspective (Goedkoop et al., 2008). The total environmental impacts of a consumption pattern was estimated by combining the impacts determined for each component with the amount consumed of the component. To arrive at a single impact score for each of the questionnaire respondents, the endpoint indicator results were weighted and summed applying weights in accordance with the hierarchical perspective i.e. weight applied to human health endpoint indicator is 300 , to ecosystem indicator is 400 and to resources indicator is 300 .

Contribution analysis was carried out in order to investigate the contributions of different consumption components to midpoints as well as endpoints. Similarly, the contributions of individual midpoints to the endpoint indicators, and the contributions of the 3 endpoints to the single score were also analysed.

To explore the dependencies among the endpoint results and single score results, a correlation analysis was carried out. Linear correlations were estimated using the Pearson correlation coefficient $(R)$ and coefficient of determination $\left(R^{2}\right)$, while nonlinear correlation was analyzed with nonparametric rank based Spearman's rho $(\rho)$ (Berthouex and Brown, 1994; Chen and Popovich, 2002; Reimann et al., 2011). For the obtained correlation coefficients, the statistical significance was assessed.

In order to investigate the influence of demography, consumption levels, and other lifestyle aspects on the environmental burden of the individual respondents, cluster analysis was used to categorize the 
Kalbar, P. P., Birkved, M., Hauschild, M. Z., Kabins, S., \& Nygaard, S. E. (2018). Environmental I mpact of Urban Consumption Patterns: Drivers and Focus Points. Resources, Conservation and Recycling 137, $260-269$. DOI: $10.1016 /$ j. resconrec. 2018.06.019

1281 respondents into distinct consumer clusters, using the three endpoints (normalized values) as descriptors. The most commonly used cluster analysis method, the k-means method was used (Everitt et al., 2011; Reimann et al., 2011). All the computations employed for obtaining clusters were carried out using MATLAB®R2013b version 8.2.0.701.

Once the clusters were identified, behavioural aspects, such as choice of diet, private car ownership, household size, etc., of these clusters were obtained from the questionnaire data returned by the respondents belonging to the cluster.

\section{Results and discussion}

Summarized results of the impact assessment are shown in Figure 2 which depicts variations of endpoint and single scores across all respondents for each of the six consumption components. Road transportation shows the largest variation in impacts for all three endpoints, reflecting the different impact potentials of the road transport options utilized by the respondents, such as private car, public train and bus, as well as bicycle. In the data set there were 440 respondents (34\%) who indicated that they did not own a private car, hence this consumption component created considerable variation among the respondents in the impacts from road transportation. Following sub-sections discuss the results of contribution analysis and cluster analysis in detail. 
Kalbar, P. P., Birkved, M., Hauschild, M. Z., Kabins, S., \& Nygaard, S. E. (2018). Environmental Impact of Urban Consumption Patterns: Drivers and Focus Points. Resources, Conservation and Recycling 137, $260-269$. DOI: $10.1016 /$ j.resconrec.2018.06.019
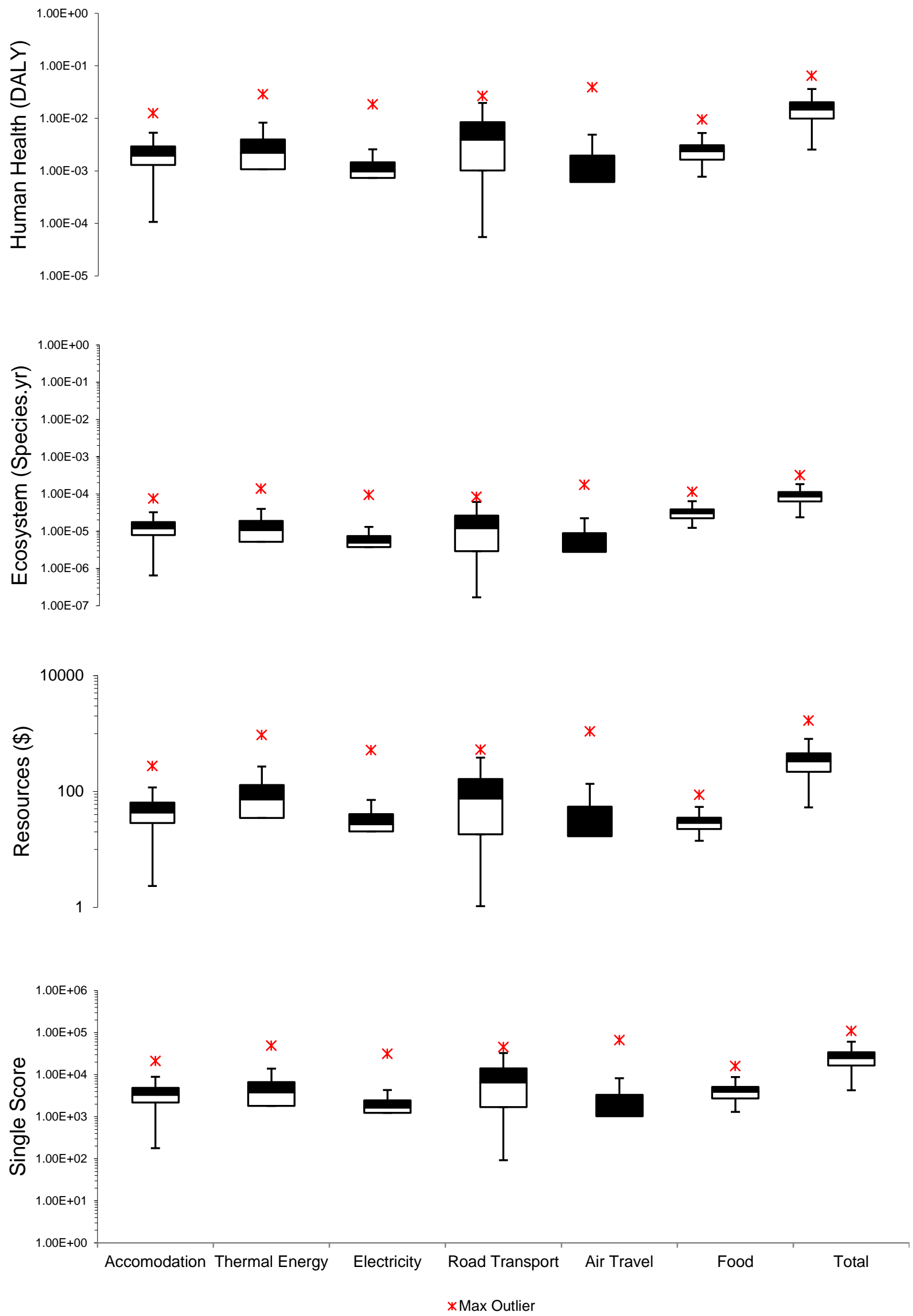

Figure 2: Variation of the endpoints and single score for the 1281 respondents (pls. note log-scale has been used on the $y$-axis for resource depletion endpoint) 
Kalbar, P. P., Birkved, M., Hauschild, M. Z., Kabins, S., \& Nygaard, S. E. (2018). Environmental Impact of Urban Consumption Patterns: Drivers and Focus Points. Resources, Conservation and Recycling 137, $260-269$. DOI: $10.1016 /$ j. resconrec. 2018.06.019

\subsection{Contribution analysis and exploration of the interdependency of endpoints}

A contribution analysis at midpoint level shown in Figure 3 reveals that food, road transport and accommodation (construction of house) jointly dominate most of the impact categories. The analysis further reveals that the six consumption components contribute more or less equally to the Climate Change impact. Food consumption contributes most to the ecotoxicity, eutrophication, and agricultural land occupation impacts. Detailed results of the midpoints contribution analysis are presented in (Kalbar et al., 2016). 


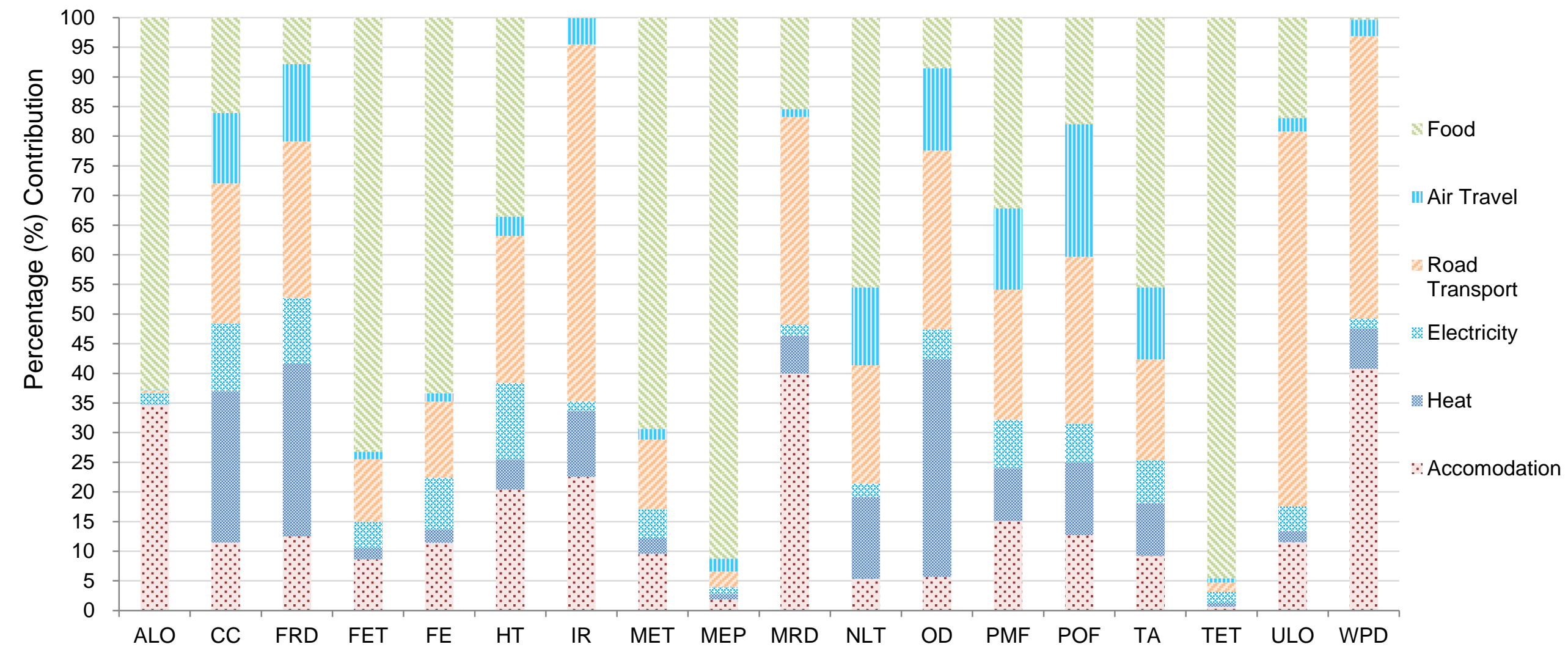

Figure 3: Average contributions of consumption components in 18 midpoint impact categories of ReCiPe 2008

(ALO - Agricultural Land Occupation; CC - Climate Change; FRD - Fossil Depletion; FET - Freshwater Ecotoxicity ; FE - Freshwater Eutrophication; HT - Human Toxicity; IR Ionizing Radiation; MET - Marine Ecotoxicity; MEP - Marine Eutrophication; MRD - Metal Depletion; NLT - Natural Land Transformation; OD - Ozone Depletion; PMF Particulate Matter Formation; POF - Photochemical Oxidant Formation; TA- Terrestrial Acidification; TET - Terrestrial Ecotoxicity; ULO - Urban Land Occupation; WPD - Water Depletion ) 
Kalbar, P. P., Birkved, M., Hauschild, M. Z., Kabins, S., \& Nygaard, S. E. (2018). Environmental Impact of Urban Consumption Patterns: Drivers and Focus Points. Resources, Conservation and Recycling 137, $260-269$. DOI: $10.1016 /$ j. resconrec. 2018.06.019

With its focus on the overarching areas of protection Human health, Ecosystems and Resources, the endpoint contribution analysis provides a complimentary perspective on the impacts from the consumption components. As it can be seen from Figure 4 (scalar graph of 1281 respondents) and summarized contributions in Table 1, the human health endpoint is mainly dominated by the contribution from the road transport component (component $4-31.5 \%$ contribution), whereas the food consumption has the largest contribution to the ecosystems endpoint (component $6-35.4 \%$ contribution). While the resource consumption endpoint is equally dominated by the thermal energy and road transport consumption components (components 2 and 4 respectively - app. 27\% contribution by each). Aggregating across the three areas of protection using hierarchical weighting, the single score is mainly influenced by road transport exhibiting almost similar contribution pattern (few minor deviations from this pattern) as of contributions to the human health endpoint. 
Kalbar, P. P., Birkved, M., Hauschild, M. Z., Kabins, S., \& Nygaard, S. E. (2018). Environmental I mpact of Urban Consumption Patterns: Drivers and Focus Points. Resources, Conservation and Recycling 137, $260-269$. DOI: $10.1016 /$ j. resconrec. 2018.06.019
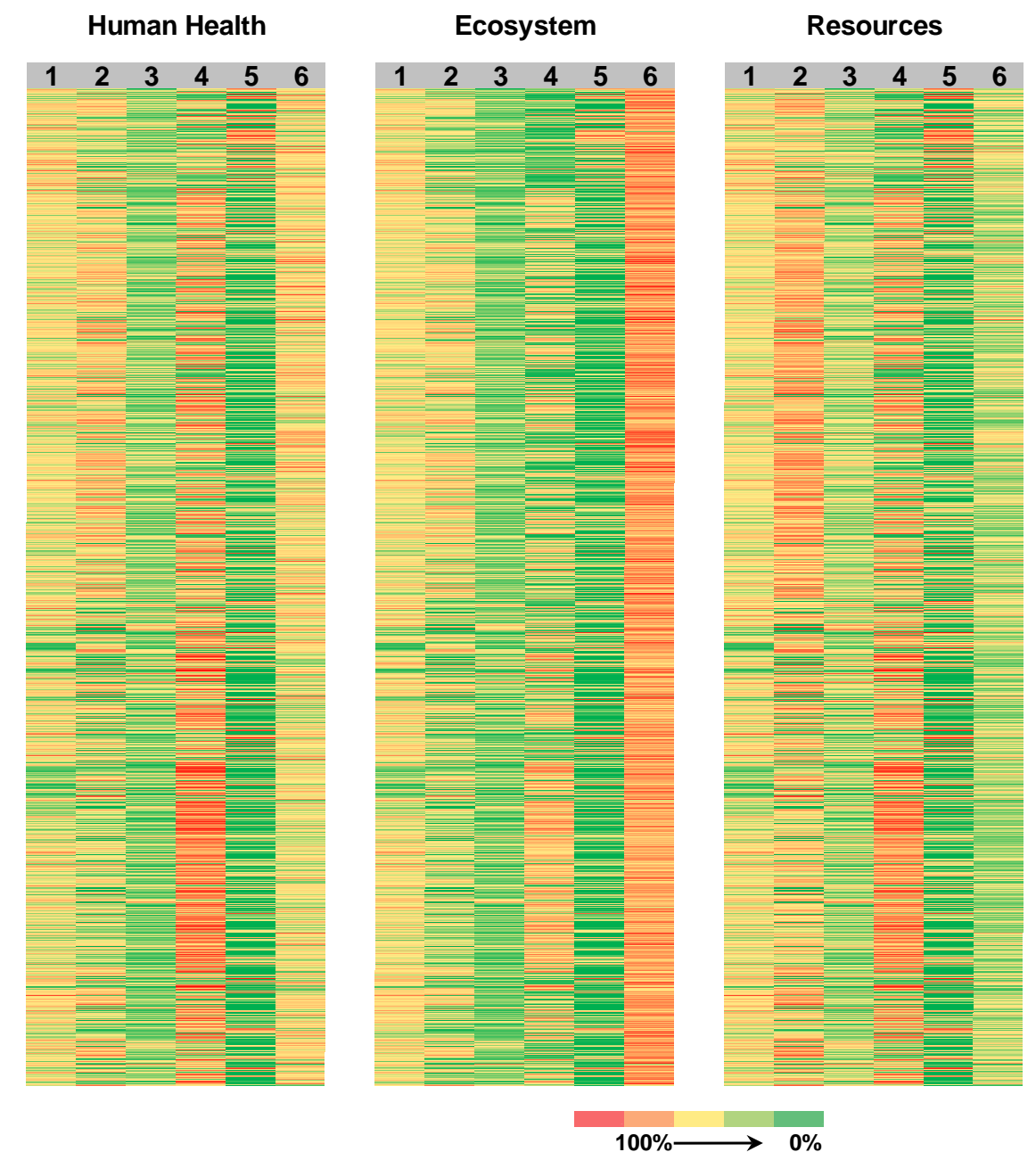

\section{Single Score $(\mathrm{H})$}

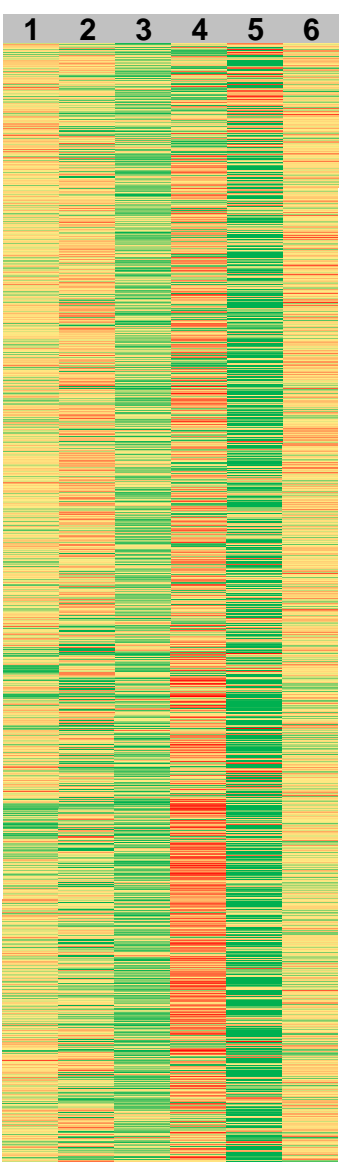

Figure 4: Contribution to endpoint impact categories and single score by each consumption components for all 1283 respondents. In the figure each of the rows represent impacts from respondents.

(1 - Accommodation; 2 - Thermal Energy; 3-Electricity; 4 - Road Transport; 5 - Air Travel; 6- Food ) 
Kalbar, P. P., Birkved, M., Hauschild, M. Z., Kabins, S., \& Nygaard, S. E. (2018). Environmental Impact of Urban Consumption Patterns: Drivers and Focus Points. Resources, Conservation and Recycling 137, $260-269$. DOI: $10.1016 /$ j. resconrec. 2018.06.019

Table 1: Summary of contribution analysis of endpoints and single score (values presented as percentages)

\begin{tabular}{cccccccc}
\hline & $\begin{array}{c}\text { Accommodat } \\
\text { ion }\end{array}$ & $\begin{array}{c}\text { Thermal } \\
\text { Energy }\end{array}$ & $\begin{array}{c}\text { Electricit } \\
\mathrm{y}\end{array}$ & $\begin{array}{c}\text { Road } \\
\text { Transport }\end{array}$ & $\begin{array}{c}\text { Air } \\
\text { Travel }\end{array}$ & $\begin{array}{c}\text { Foo } \\
\mathrm{d}\end{array}$ & $\begin{array}{c}\text { Tota } \\
\text { I }\end{array}$ \\
\hline $\begin{array}{c}\text { Human } \\
\text { Health } \\
\text { (DALY) }\end{array}$ & 14.6 & 18.4 & 8.7 & 32.0 & 10.3 & $\begin{array}{c}15 . \\
9\end{array}$ & 100 \\
\hline $\begin{array}{c}\text { Ecosystems } \\
\text { (species.yr) }\end{array}$ & 15.5 & 15.5 & 7.8 & 17.3 & 8.1 & $\begin{array}{c}35 . \\
8\end{array}$ & 100 \\
\hline $\begin{array}{c}\text { Resources } \\
(\$)\end{array}$ & 14.2 & 26.5 & 10.7 & 27.5 & 12.6 & 8.4 & 100 \\
\hline $\begin{array}{c}\text { Single } \\
\text { Score }(\mathrm{H})\end{array}$ & 14.6 & 18.5 & 8.8 & 32.0 & 10.3 & $\begin{array}{c}15 . \\
8\end{array}$ & 100 \\
\hline
\end{tabular}

To further investigate the reason for the similarities observed for the consumption component contributions to the human health endpoint on the single score, the contributions of the individual midpoints to the endpoints was further explored. As illustrated in Figure 5, contributions to the endpoints mainly originate from the following mid-point indicators: climate change, particulate matter formation, ionizing radiation and fossil depletion along with only a miniscule contribution from human toxicity, terrestrial ecotoxicity, and metal depletion. All other midpoints contribute marginally to the three endpoints. 
Kalbar, P. P., Birkved, M., Hauschild, M. Z., Kabins, S., \& Nygaard, S. E. (2018). Environmental I mpact of Urban Consumption Patterns: Drivers and Focus Points. Resources, Conservation and Recycling 137, $260-269$. DOI: $10.1016 /$ j. resconrec. 2018.06.019

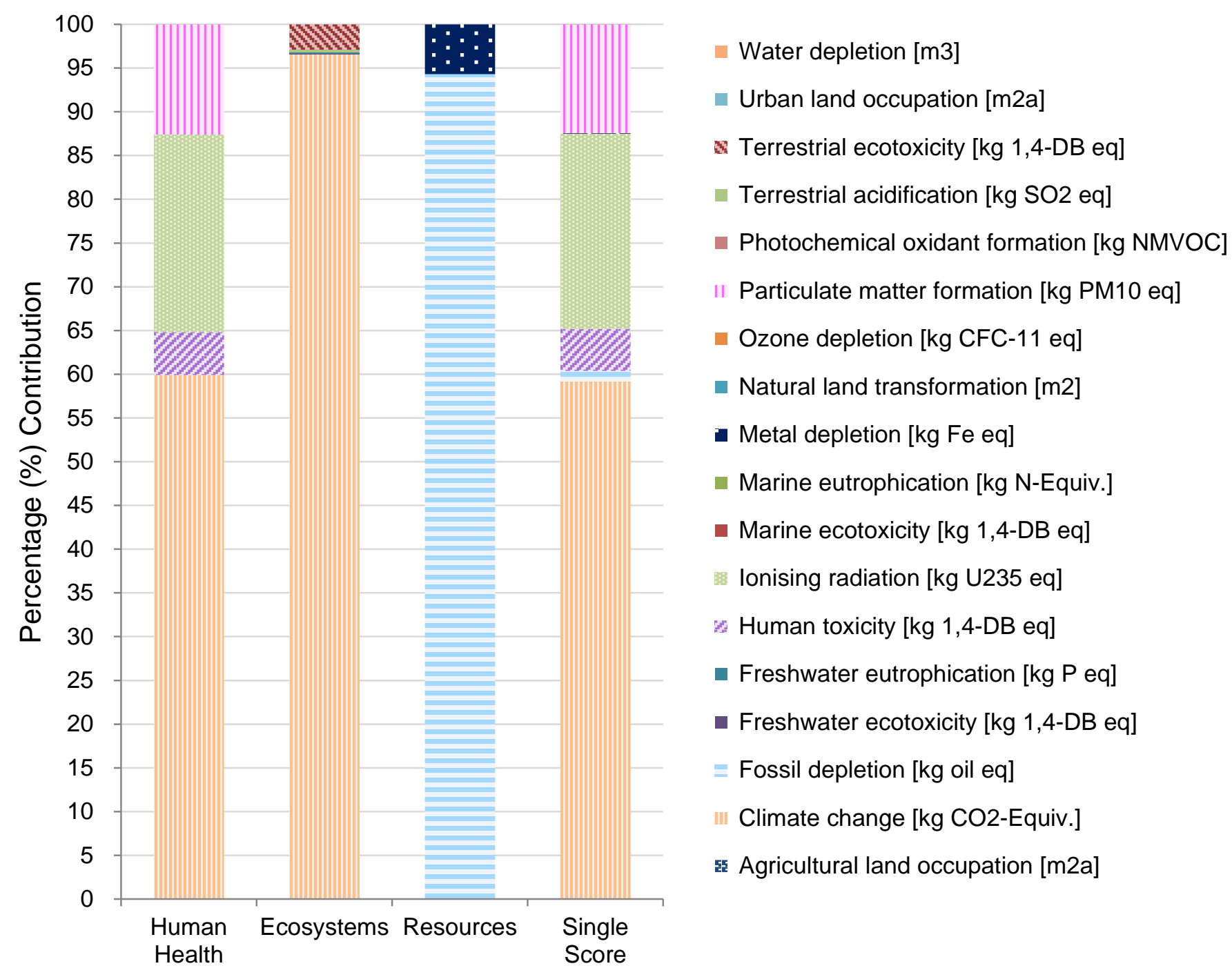

Figure 5: Contribution of midpoints to endpoints and single score

This pattern is caused by the fact that not all the midpoints have been characterized completely in order to be taken into account by the endpoints (EC-JRC, 2011; Goedkoop et al., 2008; Van Hoof et al., 2013). The incomplete transformation is further explained in Table 2, where the midpoints contributing to each of the 3 endpoints (as defined by the ReCiPe methodology) are grouped and presented along with their groupwise contributions of the 3 endpoints. For example, in Table 2 there are six midpoints contributing to the human health endpoint. However, the road transport component is the most environmentally taxing consumption component (contributing with $31.5 \%$ ). Since the transport component has impact on all six midpoints contributing to the human health endpoint, road transport inevitably will contribute more to the human health endpoint, which is also seen from Table 1. Similarly, the ecosystem endpoint resulting from food consumption is influenced by no less than 9 midpoints. As per Figure 3, food consumption is known to contribute significantly to all 9 midpoints 
Kalbar, P. P., Birkved, M., Hauschild, M. Z., Kabins, S., \& Nygaard, S. E. (2018). Environmental I mpact of Urban Consumption Patterns: Drivers and Focus Points. Resources, Conservation and Recycling 137, $260-269$. DOI: $10.1016 /$ j. resconrec. 2018.06.019

covered by the ecosystem endpoint and hence food consumption contributes most to the ecosystem endpoint (54.1\%, refer to Table 2) as also shown in Table 1. However, it should be noted that the extent to which each midpoint contributes to road transport and food consumption does not remain constant at endpoint level, as each of the midpoints are characterized to endpoints through different damage models (Goedkoop et al., 2008). Hence, the relative mid point contribution to each endpoint depends not just on the severity of the midpoint indicators in terms of causing environmental damage but also on the completeness of the damage model. The more complete the damage model is for a particular midpoint, the larger its contribution to the endpoint (damage to human health, ecosystem and resources) will be (Goedkoop et al., 2008; Hauschild et al., 2013). For example, presently climate change related impacts assessed by the most complete damage models covers both the damages to human health and biodiversity (EC-JRC, 2011).

Table 2: Contribution of midpoints to endpoints. Estimated based on Kalbar et al. (2016) (values are in percentages)

\begin{tabular}{ccccccccc}
\hline & & $\begin{array}{c}\text { Accomm } \\
\text { odation }\end{array}$ & $\begin{array}{c}\text { Thermal } \\
\text { Energy }\end{array}$ & Electricity & $\begin{array}{c}\text { Road } \\
\text { Transport }\end{array}$ & Air Travel & Food & Total \\
\hline $\begin{array}{c}\text { Midpoints mainly } \\
\text { contributing to } \\
\text { Human Health }\end{array}$ & $\begin{array}{c}\text { CC, HT, IR, } \\
\text { PMF, POF, OD }\end{array}$ & 14.7 & 16.6 & 7.6 & 31.5 & 11.6 & 18.1 & 100 \\
\hline $\begin{array}{c}\text { Midpoints mainly } \\
\text { contributing to } \\
\text { Ecosystems }\end{array}$ & $\begin{array}{c}\text { ALO, CC, FET, } \\
\text { FE, MET, NLT, } \\
\text { TA, TET, ULO }\end{array}$ & 11.4 & 6.4 & 5.2 & 17.9 & 5.0 & 54.1 & 100 \\
\hline $\begin{array}{c}\text { Midpoints mainly } \\
\text { contributing to } \\
\text { Resources }\end{array}$ & MRD, FRD & 26.2 & 17.8 & 6.5 & 30.7 & 7.2 & 11.6 & 100 \\
\hline
\end{tabular}

(ALO - Agricultural Land Occupation; CC - Climate Change; FRD - Fossil Depletion; FET - Freshwater Ecotoxicity ; FE Freshwater Eutrophication; HT - Human Toxicity; IR - Ionizing Radiation; MET - Marine Ecotoxicity; MRD - Metal Depletion; NLT Natural Land Transformation; OD - Ozone Depletion; PMF - Particulate Matter Formation; POF - Photochemical Oxidant Formation; TA- Terrestrial Acidification; TET - Terrestrial Ecotoxicity; ULO - Urban Land Occupation) 
Kalbar, P. P., Birkved, M., Hauschild, M. Z., Kabins, S., \& Nygaard, S. E. (2018). Environmental I mpact of Urban Consumption Patterns: Drivers and Focus Points. Resources, Conservation and Recycling 137, $260-269$. DOI: $10.1016 /$ j. resconrec. 2018.06.019

It was also found that human health dominates the single score with $98.67 \%$, ecosystem contributes with (only) $0.01 \%$ while the resources endpoint contributes with $1.32 \%$. This pattern is caused by the large values obtained for human health after endpoint normalization. Upon midpoint and endpoint normalization the normalized values are highest for those indicators for which normalization references are weak i.e. there is data gap in the determination of the normalization reference, which is hence likely to be underestimated (Norris, 2001; Rogers and Seager, 2009; Van Hoof et al., 2013). This is likely a part of the cause why the human health contribution dominates the single score. This addition of bias by external normalization has recently been discussed in details by Kalbar et al., (2017) and Cucurachi et al. (2017).

The correlations among the three endpoints and single score are subsequently further explored in order to locate any preferential dependency (i.e. if increase in one indicator results in increases in other indicators and vice-versa) among endpoints and single score indicators, as discussed by (Seppa et al., 2002). Table 3 shows the correlations among endpoints and single score, which reveals that endpoints and the single score are strongly correlated and hence are preferentially dependent.

Table 3: Pearson correlation coefficient (R) among endpoints and single score. $R^{2}$ values are given in brackets. All the values are significant at 0.05 level.

Single Score Human Health Ecosystems Resources

\begin{tabular}{lcccc}
\hline Single Score & 1.000 & $\begin{array}{c}1.000 \\
(1.000)\end{array}$ & $\begin{array}{c}0.975 \\
(0.951)\end{array}$ & $\begin{array}{c}0.980 \\
(0.960)\end{array}$ \\
\hline Human Health & -- & 1.000 & $\begin{array}{c}0.975 \\
(0.950)\end{array}$ & $\begin{array}{c}0.979 \\
(0.959)\end{array}$ \\
\hline Ecosystems & -- & -- & 1.000 & $\begin{array}{c}0.960 \\
(0.922)\end{array}$ \\
\hline Resources & -- & -- & -- & 1.000 \\
\hline
\end{tabular}


Kalbar, P. P., Birkved, M., Hauschild, M. Z., Kabins, S., \& Nygaard, S. E. (2018). Environmental I mpact of Urban Consumption Patterns: Drivers and Focus Points. Resources, Conservation and Recycling 137, $260-269$. DOI: $10.1016 /$ j. resconrec. 2018.06.019

\subsection{Creation of clusters - key parameters influencing environmental burden of urban consumption patterns}

The urban consumption pattern data of the 1281 respondents presented in this study has multiple dimensions which required detailed analyses in order to identify the various parameters that control, or rather influence the environmental burden related to urban consumption. Hence a cluster analysis applying the k-means method and using the three endpoints as descriptors was conducted. Ten clusters (here corresponding to groups of respondents) were identified showing a distinct separation of the environmental burden (in the form of endpoints) exerted by respondents. However, out of the 10 clusters, one of the clusters (cluster 7 ) identified by the k-means algorithm consisted of only two respondents both associated with very high endpoint values (showing extremely high impacting consumption patterns) and due to it's rather low representativeness, this group was not considered for further analysis. Figure 6, shows the 3-D plot and further 2-D plots of the nine clusters found representative for 1281 respondents. 


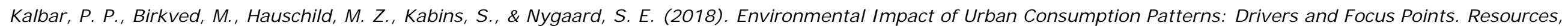
Conservation and Recycling 137, 260-269. DOI: 10.1016/j. resconrec.2018.06.019
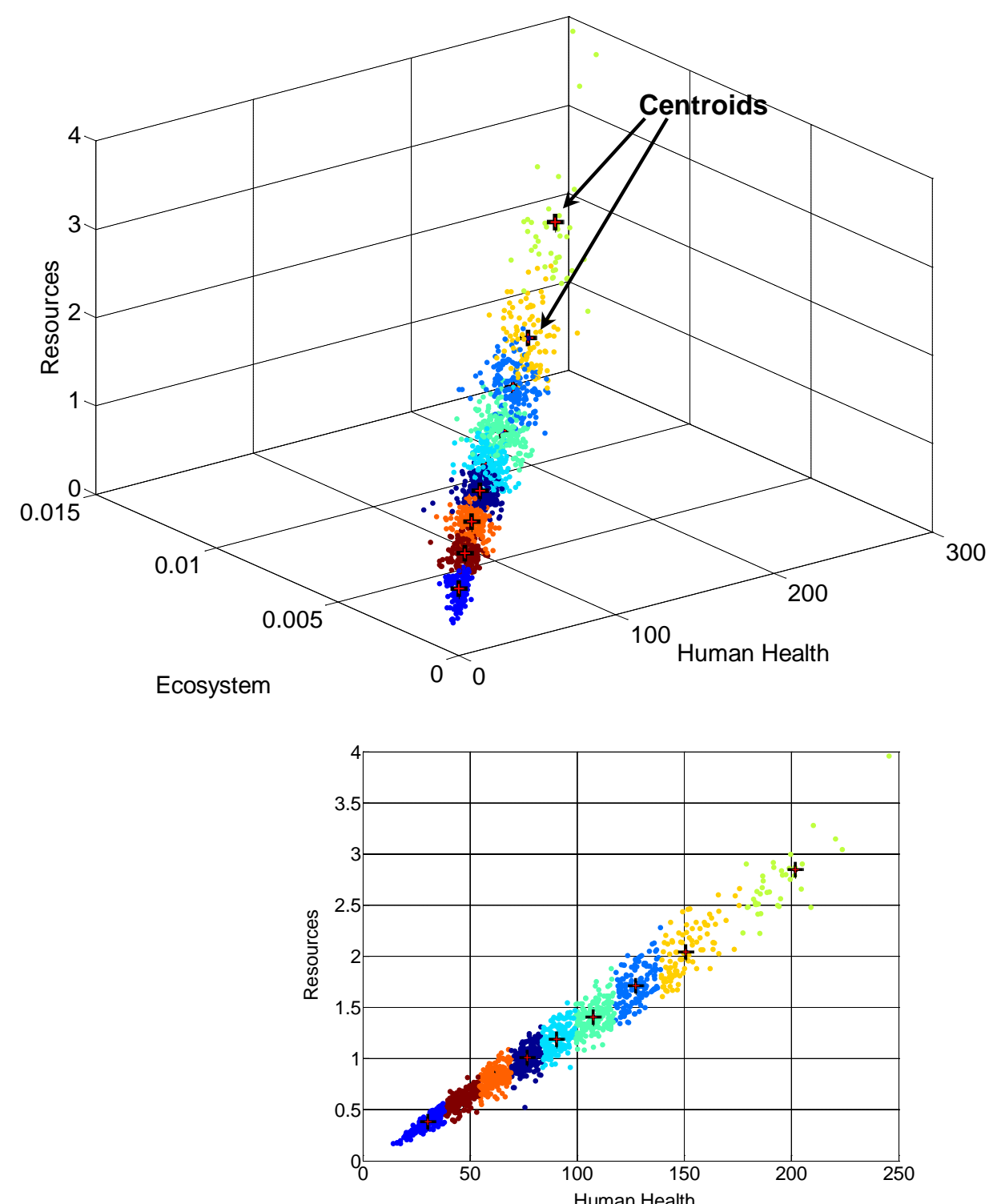
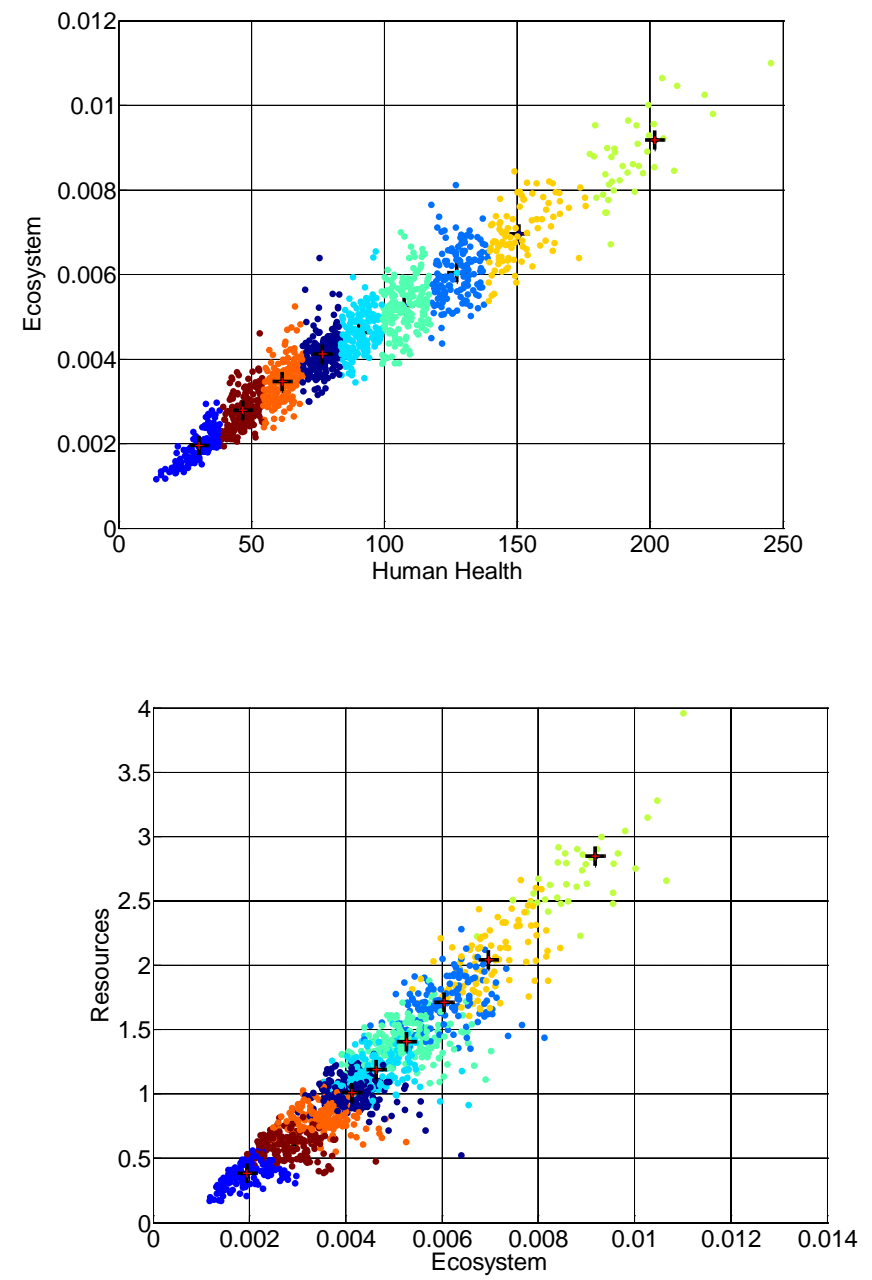

Figure 6: Results of cluster analysis of 1281 respondents' dataset 
Kalbar, P. P., Birkved, M., Hauschild, M. Z., Kabins, S., \& Nygaard, S. E. (2018). Environmental I mpact of Urban Consumption Patterns: Drivers and Focus Points. Resources, Conservation and Recycling 137, $260-269$. DOI: $10.1016 /$ j. resconrec. 2018.06.019

In Table 4, detailed characteristics of each of the clusters are presented. The first column represents the cluster number while the second column contains the number of respondents in the respective cluster. In the third column the arithmetic mean of the single score of the respondents in the cluster is provided. These results reveal that there is a distinct difference between the environmental burdens exerted by the respondents of each of these clusters and hence the results are arranged in ascending order of the single score of each (respondent) cluster.

The remaining columns in Table 4 provide the arithmetic means of the parameters influencing the environmental burden of the respondents in the respective cluster. It should be noted that for some of the parameters (marked with "\#") relative values in terms of percentages are provided. For example, income per person given under demography (parameter 1) amounts to $41.7 \%$ of cluster number 8 aggregating up through the sub-clusters to cluster number 10 thus reaching $100 \%$. The correlation plots of the arithmetic means of the controlling parameters presented in Table 4 and the arithmetic mean of the single scores obtained for each cluster are shown in Figure 7. The various parameters covering demography, consumption levels and lifestyle aspects were further analyzed in terms of the respondents in each of the clusters. These analyses are discussed in details in the following. 


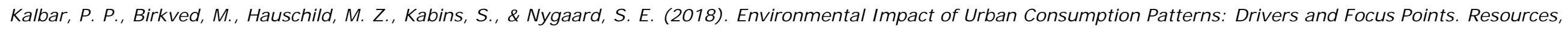
Conservation and Recycling 137, 260-269. DOI: 10.1016/j.resconrec.2018.06.019

Table 4: Results of cluster analysis showing effect of lifestyle aspects, demographic parameters and consumption levels on environmental burden. Clusters are arranged lower to higher environmental burdens. Cluster 7 has been left out due to its minute (two respondents) size.

\begin{tabular}{|c|c|c|c|c|c|c|c|c|c|c|c|c|c|}
\hline \multirow{2}{*}{$\begin{array}{l}\text { Cluster } \\
\text { Number }\end{array}$} & \multirow{2}{*}{$\begin{array}{l}\text { Number of } \\
\text { Respondents } \\
\text { in the Cluster }\end{array}$} & \multirow{2}{*}{$\begin{array}{l}\text { Single Score } \\
\text { (pt.) }\end{array}$} & \multicolumn{3}{|c|}{ Demography } & \multicolumn{4}{|c|}{ Consumption Levels } & \multicolumn{4}{|c|}{ Lifestyle Aspects } \\
\hline & & & $1^{\#}$ & $2^{\#}$ & 3 & $4^{\#}$ & $5^{\#}$ & $6^{\#}$ & $7^{\#}$ & 8 & 9 & 10 & 11 \\
\hline 8 & 148 & 9192 & 41.7 & 67.1 & 34.5 & 9.25 & 25.3 & 10.8 & 14.2 & 80 & 116 & 66 & 2.95 \\
\hline 6 & 167 & 14182 & 50.9 & 76.9 & 40.5 & 17.49 & 32.7 & 19.8 & 22.7 & 54 & 107 & 37 & 2.53 \\
\hline 5 & 165 & 18731 & 55.8 & 73.7 & 44.8 & 21.16 & 38.0 & 29.9 & 26.6 & 36 & 86 & 22 & 2.54 \\
\hline 9 & 187 & 23283 & 64.3 & 86.8 & 51.9 & 31.23 & 44.5 & 33.4 & 29.7 & 22 & 61 & 11 & 2.6 \\
\hline 3 & 159 & 27452 & 69.5 & 88.1 & 54.4 & 27.43 & 48.3 & 40.5 & 36.0 & 12 & 31 & 4 & 2.65 \\
\hline 2 & 175 & 32686 & 73.5 & 89.9 & 53.6 & 32.36 & 52.6 & 43.2 & 38.6 & 14 & 17 & 6 & 2.53 \\
\hline 4 & 144 & 38678 & 80.1 & 99.2 & 57.2 & 36.90 & 63.9 & 60.6 & 45.5 & 13 & 9 & 0 & 2.17 \\
\hline 1 & 94 & 45841 & 87.5 & 96.0 & 57.4 & 61.97 & 71.9 & 69.2 & 49.8 & 9 & 9 & 2 & 2.02 \\
\hline 10 & 42 & 61387 & 100.0 & 100.0 & 56.1 & 100.00 & 100.0 & 100.0 & 100.0 & 4 & 4 & 2 & 1.76 \\
\hline \multicolumn{3}{|c|}{$\begin{array}{l}\text { Pearson Correlation Coefficient }(R) \text { between } \\
\text { Single Score with respective columns* }\end{array}$} & 0.99 & 0.90 & 0.82 & 0.95 & 0.99 & 0.99 & 0.95 & -0.82 & -0.89 & -0.76 & -0.93 \\
\hline \multicolumn{3}{|c|}{$\begin{array}{r}\text { Coefficient of Determination }\left(R^{2}\right) \text { between } \\
\text { Single Score with respective columns }\end{array}$} & 0.98 & 0.82 & 0.67 & 0.91 & 0.99 & 0.99 & 0.90 & 0.67 & 0.79 & 0.57 & 0.87 \\
\hline
\end{tabular}

\# Values are relative percentages (internally normalized)

*all the correlation values are significant at 0.05 level

1 - Income per person per year

7 - Electricity Consumption per person per year

2 - Income per household per year

3 - Average age of the respondents in the cluster

4 - Distance travelled using airplane per year

5 - House Area per person

Number respondents with vegetarian diet in the cluster

9 - Number of respondents not having private car

10 - Number of respondents with vegetarian diet and do not have private Car

6 - Thermal Energy Consumption per person per year

11 - Average household size of the respondents in the cluster 
Kalbar, P. P., Birkved, M., Hauschild, M. Z., Kabins, S., \& Nygaard, S. E. (2018). Environmental I mpact of Urban Consumption Patterns: Drivers and Focus Points. Resources, Conservation and Recycling 137, $260-269$. DOI: $10.1016 /$ j. resconrec. 2018.06.019

\subsubsection{Effect of demographic parameters on environmental burden}

Demographic parameters such as individual income level, household income level and age of the respondents (parameters 1,2 and 3 respectively) were analyzed for their influence on the environmental burdens exerted by the respondents. As it can be seen from Table 4 and Figure $7 \mathrm{a}$, the individual income levels and household income levels are strongly correlated with the environmental burdens exerted by respondents within the respective clusters $\left(R^{2}\right.$ values of 0.98 and 0.82 respectively). This strong correlation would be expected considering the fact that the higher the income, the more people are likely to spend.

However, interestingly, in our analysis it was found that the age of the respondents is also strongly correlated with the environmental burdens exerted by the respondents. As it can be seen from Table 4 and Figure $7 \mathrm{c}$, the age of the respondents correlates well with the single score, indicating that the younger the respondent the lower environmental burden exerted by the respondent $\left(R^{2}\right.$ value of 0.67$)$.

\subsubsection{Effect of consumption levels on environmental burden}

To assess how consumption levels of some of the consumption categories affect environmental burden, four consumption categories were analyzed viz. distance travelled using airplane, accommodation area, thermal energy consumption and electricity consumption (parameters 4-8 respectively). It was found that) all four consumption parameters correlate strongly with the environmental burden ( $R^{2}$ values are in the range of 0.90 to 0.99 ) (pls. refer to Table 4 and Figure $7 \mathrm{~b}$. This observation once again underlines that the higher the consumption level, the higher the environmental burden exerted by the respondents.

Indications are that consumption will keep on increasing due to the way our current economies are constructed. However, choosing more sustainable consumption patterns, parts of the impacts can potentially be mitigated as is evident from e.g. the increasing support for consumption oriented climate change mitigation policies (Girod et al., 2014, 2013). As demonstrated by Girod et al. (2014), shifts in consumption patterns (e.g., changes in diets, travel modes), selecting items/services with lower GHG intensities (e.g., renewable energy supplies, public transport etc.), changing operation habits of the household equipments (e.g., lowering indoor temperature, taking less baths etc.) can assist in keeping below the $+2^{\circ} \mathrm{C}$ climate change bar.

\subsubsection{Effect of lifestyle aspects' on environmental burden}

Four additional parameters concerning lifestyle aspects were analyzed to see how they influence the environmental burdens of urban consumption patterns. As presented in Table 4 and Figure $7 \mathrm{~d}$, the number of respondents following a vegetarian nutrition strategy (parameter 8 ) in each of the clusters correlates negatively $\left(R^{2}\right.$ value between -0.82 and --0.67) with the environmental burden exerted by the clusters. This implies that respondents adopting a vegetarian nutrition strategy exerts a lower consumption related environmental burden. In Cluster 8 (with the lowest average single score), 80 out of 148 respondents have indicated that they have adopted a vegetarian nutrition strategy and in 
Kalbar, P. P., Birkved, M., Hauschild, M. Z., Kabins, S., \& Nygaard, S. E. (2018). Environmental I mpact of Urban Consumption Patterns: Drivers and Focus Points. Resources, Conservation and Recycling 137, $260-269$. DOI: $10.1016 /$ j. resconrec. 2018.06.019

Cluster 10 (with the highest average single score) only 4 respondents (out of 42 ) have indicated that they have adopted a vegetarian nutrition strategy. The average environmental impact of Cluster 8 is 6.7 times lower than Cluster 10 if compared based on single score values.

A similar trend was observed for the lifestyle aspect related to private car ownership (pls. refer to Table 4 and Figure 7d). The number of respondents in each cluster not having a private car (parameter 9) correlates negatively with single score results $\left(R^{2}\right.$ value between -0.89 and -0.79$)$. In Cluster 8 (with the lowest average single score), 116 respondents do not own a private car while in Cluster 10 (with the highest average single score) only 4 respondents do not have a private car. As expected this reveals that respondents owning private cars exert a higher environmental burden.

When the data were analyzed by combining and applying both of these descriptors (i.e. vegetarian nutrition strategy and private car ownership), a similar trend of negative correlation was observed (refer to Table 4 and Figure 7d). This illustrates how compounded lifestyle aspects affect the environmental burden of urban consumption patterns strongly.

Finally, as shown in Table 4 and Figure 7c, the average household size of the respondents in each cluster (parameter 11) was correlated with the average single scores obtained for each cluster. This correlation analysis further revealed that the household size correlates negatively with the single scores $\left(\left(R^{2}\right.\right.$ value betwen-0.93 and -0.87$)$. This highlights that the larger their household size the lower the environmental burden exerted by the respondents. 


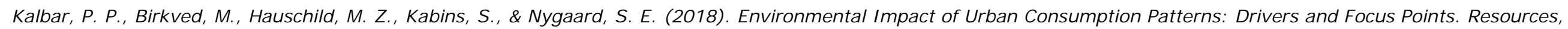
Conservation and Recycling 137, 260-269. DOI: 10.1016/j.resconrec.2018.06.019
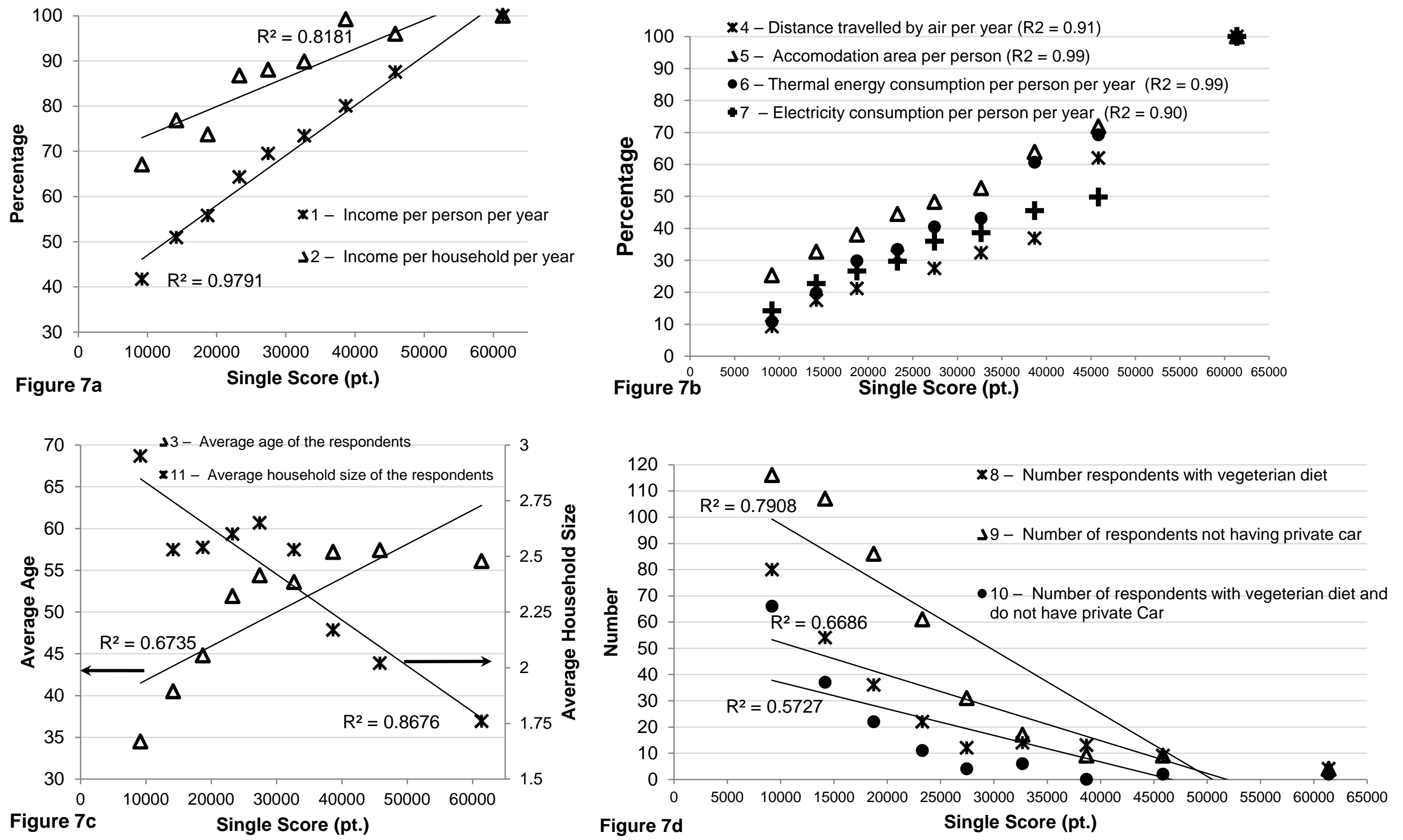

Figure 7: Correlation plots between single score and different parameters influencing the environmental burden induced by urban consumption patterns. 
Kalbar, P. P., Birkved, M., Hauschild, M. Z., Kabins, S., \& Nygaard, S. E. (2018). Environmental I mpact of Urban Consumption Patterns: Drivers and Focus Points. Resources, Conservation and Recycling 137, $260-269$. DOI: $10.1016 /$ j.resconrec.2018.06.019

\subsection{Limitations and future prospects}

The analyses presented in this paper are based on the PM-LCA model presented in details in (Kalbar et al., 2016), hence the work presented here have the same inherent limitations as already elaborated in Kalbar et al. (2016). Additionally, it should be noted that because of the lack of other similar studies in the literature it has not been possible to compare/validate the results of the present study against other studies.

The results of our study have been analyzed on a relative basis, i.e. how one cluster performs in relation to another. However, by using the recent framework proposed by Bjørn and Hauschild (2015) it is possible to assess the absolute performance of the respondents. Applying an absolute assessment approach could potentially answer the question whether the consumption and hence environmental performance of the respondents even in the least burdensome cluster (Cluster number 8) is sustainable in an absolute sense and thus whether the environmental burden exerted by the consumption of respondents exceeds their share of the space within the planetary boundaries (Rockström et al., 2009).

The results of our study can help to devise multipronged approaches to quantify and eventually minimize environmental impacts from urban consumption. For example, contribution analysis results help to investigate highly contributing consumption components (such as e.g. food and road transport). Quantitative environmental performance assessment of lifestyle aspects can help to disseminate awareness about what kind of actions Danish urban residents can take to improve their environmental performance and thus lower the burden the exert on the environment in a truly holistic manner.

\section{Conclusions}

Our work provides detailed results and analysis relating to the environmental burden exerted by the urban consumption patterns from residents of urban areas in Denmark. The study was based on a first of its kind PM-LCA approach. The study revealed that food consumption dominates most of the impacts at midpoint level. However, at the endpoint level road transport dominates two endpoints (human health and resources) whereas food consumption "only" dominates ecosystem endpoints. The detailed analysis presented in our paper on midpoint contributions to the individual endpoints clarified that there is much variation in the contributions from the different midpoints to the endpoints. Some midpoints such as climate change, human toxicity, particulate matter, fossil depletion and ionizing radiation contribute more to endpoints than the other midpoints. This skewed contribution was also evident by the facts that the ReCiPe method does not include characterization factors allowing for all midpoint impacts to be adequately transformed into endpoint impacts and combined with the fact that the existing damage models are not complete except for climate change (comparatively more complete than other categories). 
Kalbar, P. P., Birkved, M., Hauschild, M. Z., Kabins, S., \& Nygaard, S. E. (2018). Environmental I mpact of Urban Consumption Patterns: Drivers and Focus Points. Resources, Conservation and Recycling 137, $260-269$. DOI: $10.1016 /$ j.resconrec.2018.06.019

Cluster analysis using three endpoints as descriptors was carried out and nine distinct clusters (i.e. respondent groups) were identified each performing (significantly) differently in terms of environmental performance. It was found that the demographic parameters such as income level and age of the respondents have at least partial direct/indirect effect on the environmental burden exerted by the respondents. One additional cause beyond income that could be responsible for the observed relation between impact and age could also (i.e. on top of income) be the environmental awareness and consciousness of Danish youth. It was also found that consumption levels of thermal energy, electricity, air travel distance and area of the house directly affect the environmental burden reflecting that the applied technologies are among the main contributors to overall environmental impacts. However, thermal energy consumption and area of the house are more strongly correlated with environmental burden than the other parameters. Lifestyle aspects, such as choice of diet, use of private car and household size, were found to be strongly correlated with the environmental burden exerted by the consumers. By further analysis of the dataset it was found that the higher the number of respondents with vegetarian diet and no private car, the lower the environmental burden exerted by the respective respondent groups. This shows that consumption related impacts can be mitigated through a palette of policies intended to reduce consumption levels and changing the characteristics of the consumption (life style changes). We hope the results of this study will help to articulate policies to curtail the environmental impacts from urban consumption patterns in a step wise manner by addressing each of the discussed influencing parameters.

\section{Acknowledgements}

The analysis part of the work was carried out during the postdoctoral tenure of the first author at DTU, Denmark and the first author acknowledges Postdoctoral fellowship received from the People Programme (Marie Curie Actions) of the European Union's Seventh Framework Programme (FP7/2007-2013) under REA grant agreement no 609405 (COFUNDPostdocDTU).

\section{References:}

Bjørn, A \& Hauschild, M. Z., 2015. Introducing carrying capacity-based normalisation in LCA: framework and development of references at midpoint level International Journal of Life Cycle Assessment, vol 20, no. 7, pp. 1005-1018. DOI: 10.1007/s11367-015-0899-2

Baiocchi, G., Minx, J., Hubacek, K., 2010. The Impact of social factors and consumer behavior on carbon dioxide emissions in the United Kingdom. J. Ind. Ecol. 14, 50-72. doi:10.1111/j.15309290.2009.00216.x

Berthouex, P. Mac, Brown, L.C., 1994. Statistics for environmental engineers. Lewis publishers. 
Kalbar, P. P., Birkved, M., Hauschild, M. Z., Kabins, S., \& Nygaard, S. E. (2018). Environmental I mpact of Urban Consumption Patterns: Drivers and Focus Points. Resources, Conservation and Recycling 137, $260-269$. DOI: $10.1016 /$ j. resconrec. 2018.06.019

Chen, P.Y., Popovich, P.M., 2002. Correlation: Parametric and nonparametric measures. Thousand Oaks, CA: Sage Publications.

Druckman, A., Jackson, T., 2009. The carbon footprint of UK households 1990-2004: A socioeconomically disaggregated, quasi-multi-regional input-output model. Ecol. Econ. 68, 20662077. doi:10.1016/j.ecolecon.2009.01.013

Ecoinvent (2010) The ecoinvent LCA database, v2.2, The ecoinvent center. www.ecoinvent.org

Ecoinvent (2014) The ecoinvent LCA database, v3.1, The ecoinvent center. www.ecoinvent.org

EC-JRC, 2011. Recommendations based on existing environmental impact assessment models and factors for life cycle assessment in European context. ILCD Handbook-International Reference Life Cycle Data System, European Union EUR24571EN. ISBN 978-92-79-17451-3.

Everitt, B.S., Landau, S., Leese, M., Stahl, D., 2011. Optimization Clustering Techniques, in: Cluster Analysis. John Wiley \& Sons, Ltd, pp. 111-142. doi:10.1002/9780470977811.ch5

Gabi 2013, http://www.gabi-software.com/international/software/gabi-software/

Gilg, A., Barr, S., 2006. Behavioural attitudes towards water saving? Evidence from a study of environmental actions. Ecol. Econ. 57, 400-414. doi:10.1016/j.ecolecon.2005.04.010

Girod, B., Detlef Peter van, V., Edgar, G.H., 2013. Global climate targets and future consumption level: an evaluation of the required GHG intensity. Environ. Res. Lett. 8, 14016. doi:10.1088/1748-9326/8/2/029501

Girod, B., van Vuuren, D.P., Hertwich, E.G., 2014. Climate policy through changing consumption choices: Options and obstacles for reducing greenhouse gas emissions. Glob. Environ. Chang. 25, 5-15. doi:10.1016/j.gloenvcha.2014.01.004

Goedkoop, M., Heijungs, R., Huijbregts, M. a. J., Schryver, A. De, Struijs, J., Zelm, R. Van, 2008. ReCiPe 2008, A life cycle impact assessment method which comprises harminised category indicators at the midpoint and the endpoint level, First edition, Report I: Characterisation. Available from internet http//www. Icia-recipe. net 126.

Hauschild, M.Z., Goedkoop, M., Guinée, J., Heijungs, R., Huijbregts, M., Jolliet, O., Margni, M., De Schryver, A., Humbert, S., Laurent, A., Sala, S., Pant, R., 2013. Identifying best existing practice for characterization modeling in life cycle impact assessment. Int. J. Life Cycle Assess. 18, 683697. doi:10.1007/s11367-012-0489-5

Kalbar, P.P., Birkved, M., Kabins, S., Nygaard, S.E., 2016. Personal-Metabolism (PM) coupled with Life Cycle Assessment (LCA) Model: Danish Case Study. Environ. Int. 91, 168-179. doi:10.1016/j.envint.2016.02.032

Kalbar, P.P., Birkved, M., Nygaard, S.E. and Hauschild, M., 2017. Weighting and Aggregation in Life Cycle Assessment: Do Present Aggregated Single Scores Provide Correct Decision Support?. Journal of Industrial Ecology, 21(6), pp.1591-1600.

Kenway, S.J., Lant, P. a., Priestley, a., Daniels, P., 2011. The connection between water and energy in cities: A review. Water Sci. Technol. 63, 1983-1990. doi:10.2166/wst.2011.070

Leach, A.M., Emery, K.A., Gephart, J., Davis, K.F., Erisman, J.W., Leip, A., Pace, M.L., D'Odorico, P., Carr, J., Noll, L.C. and Castner, E., 2016. Environmental impact food labels combining carbon, nitrogen, and water footprints. Food Policy, 61, pp.213-223.

MacQueen, J., 1967. Some methods for classification and analysis of multivariate observations, in: Proceedings of the Fifth Berkeley Symposium on Mathematical Statistics and Probability. pp. 281-297.

Mirabella, N., Allacker, K. \& Sala, S., 2018. Int J Life Cycle Assess. https://doi.org/10.1007/s11367018-1467-3

Newton, P., Meyer, D., 2012. The Determinants of Urban Resource Consumption. Environ. Behav. 44, 107-135. doi:10.1177/0013916510390494

Norris, G. a., 2001. The requirement for congruence in normalization. Int. J. Life Cycle Assess. 6, 85- 
Kalbar, P. P., Birkved, M., Hauschild, M. Z., Kabins, S., \& Nygaard, S. E. (2018). Environmental I mpact of Urban Consumption Patterns: Drivers and Focus Points. Resources, Conservation and Recycling 137, $260-269$. DOI: $10.1016 /$ j. resconrec. 2018.06.019

\section{8. doi:10.1007/BF02977843}

Reimann, C., Filzmoser, P., Garrett, R., Dutter, R., 2011. Statistical data analysis explained: applied environmental statistics with R. John Wiley \& Sons.

Rockström, A., Steffen, J.W., Noone, K., Persson, Å., Chapin III, F.S., Lambin, E., Lenton, T.M., Scheffer, M., Folke, C., Schellnhuber, H., Nykvist, B., De Wit, C.A., Hughes, T., van der Leeuw, S., Rodhe, H., Sörlin, S., Snyder, P.K., Costanza, R., Svedin, U., Falke, M., Fole, J., 2009. Planetary Boundaries: Exploring the Safe Operating Space for Humanity. Ecol. Soc. 14. doi:10.1038/461472a

Rogers, K., Seager, T.P., 2009. Environmental decision-making using life cycle impact assessment and stochastic multiattribute decision analysis: a case study on alternative transportation fuels. Environ. Sci. Technol. 43, 1718-1723. doi:10.1021/es801123h

Seppa, J., Basson, L., Norris, G.A., 2002. Frameworks for Life-Cycle Impact Assessment 5.

Schmidt J H and Muños I (2014), The carbon footprint of Danish production and consumption Literature review and model calculations. Danish Energy Agency, Copenhagen

Schmidt J H, Weidema B P, and Suh S (2010), FORWAST: Documentation of the final model used for the scenario analyses. Deliverable 6-4 of the EU FP6-project FORWAST. http://forwast.brgm.fr/

SimaPro 2014., https://www.pre-sustainability.com/news/installation-file-simapro-804

Tufféry, S., 2011. Data mining and statistics for decision making. John Wiley \& Sons.

UN, 2014. United Nations, Department of Economic and Social Affairs, Population Division, World Urbanization Prospects: The 2014 Revision, Highlights (ST/ESA/SER.A/352).

Van Hoof, G., Vieira, M., Gausman, M., Weisbrod, A., 2013. Indicator selection in life cycle assessment to enable decision making: Issues and solutions. Int. J. Life Cycle Assess. 18, 1568-1580. doi:10.1007/s11367-013-0595-z

Wentz, E.A., Gober, P., 2007. Determinants of Small-Area Water Consumption for the City of Phoenix, Arizona. Water Resour. Manag. 21, 1849-1863. doi:10.1007/s11269-006-9133-0

Westhoek, H., Lesschen, J.P., Rood, T., Wagner, S., De Marco, A., Murphy-Bokern, D., Leip, A., van Grinsven, H., Sutton, M.A., Oenema, O., 2014. Food choices, health and environment: Effects of cutting Europe's meat and dairy intake. Glob. Environ. Chang. 26, 196-205. doi:10.1016/j.gloenvcha.2014.02.004

Zhao, X., Li, N., Ma, C., 2012. Residential energy consumption in urban China: A decomposition analysis. Energy Policy 41, 644-653. doi:10.1016/j.enpol.2011.11.027 